\title{
THE OCTOBER MEETING OF THE SOCIETY
}

The two hundred thirty-first regular meeting of the Society was held at Columbia University on Saturday, October 27, 1923, extending through the usual morning and afternoon sessions. This meeting marks the transition of the Society into an incorporated body.

The Society was called to order for the transaction of business at 11.15 a. m., in Room 305 of Schermerhorn Hall, Columbia University, New York City, some fifty-five members being present. The Secretary recalled the action of the Society in previously endorsing incorporation and reported the formal action of the Council recommending the final steps. President Veblen made a general statement concerning the procedure adopted on legal advice, and recounted briefly the stages of the incorporation process, which are reported in another article in this issue.

The following resolution was then adopted unanimously: WHEREAS, a corporation has been organized under the laws of the District of Columbia, known as the American Mathematical Society, for the purpose of carrying on the work heretofore conducted by this Society; and

WHEREAS, it is the judgment of this Society that for the purpose of more efficiently prosecuting said work it is expedient to transfer to the said new corporation the entire property and assets of this Society;

NOW, THEREFORE, BE IT RESOLVED, that the officers of this Society be and they are hereby authorized and directed to transfer to the American Mathematical Society, a corporation as aforesaid, all the property and assets of this Society, including its bank deposits and choses in action, provided the said corporation shall assume and agree to pay all indebtedness and financial obligations of every kind and description for which this Society may now be liable; AND BE IT FURTHER RESOLVED, that the proper officers 
of this Society be and they are hereby empowered, to execute, acknowledge, and deliver, all contracts, deeds, and other documents necessary and proper for the carrying into effect this resolution.

The attendance at the scientific Sessions included the following sixty-eight members of the Society:

Alexander, Archibald, Ballantine, Bernstein, Birkhoff, E. W. Brown, Abraham Cohen, Cole, Cowley, L. D. Cummings, Douglas, Edmondson, Eisenhart, Fine, Fiske, Fry, (iinsburg, Gleason. Glenn, Grove, Hausle, Hawkes, Hazlett, Hebbert, Rohert Henderson, Hille, Himwich, Hodgkins, Hotelling, Huntington, Dunham Jackson, Joffe, Kasner, Kellogg, Kircher, Kline, Langman, MacColl, MacNeish, Meder, Miri॰k, Molina. Northcott, Osgood, Pell, Pfeiffer, Post, Rainich, Ranum, Reddick, R.G.D.Richardson, Ritt, Schub, Seely, Siceloff, Simons, C. E. Smith, D. E. Sinith, Sosnow, Strong, Tyler, Veblen, H. E. Webb, Weiss, M. E. Wells, H. S. White, Whittemore, J. W. Young.

At the meeting of the Council, the following forty-nine persons were elected to membership in the Society:

Miss Ethel Louise Anderton, New Haven, Conn.;

Professor Victor-Elezéar Beaupré, University of Montreal;

Dr. Harry Albert Bender, University of Illinois;

Professor Jacob Roy Bender, University of Idaho;

Miss Lucy Elizabeth Berger, College of William and Mary;

Professor Harry Birchenough, State College for Teachers, Albany, N. Y.; Mr. Harley W. Chandler, University of Florida;

Professor Myrtie Collier, Southern Branch of the University of California;

Mr. Arthur Herbert Copeland, Harvard University;

Professor Charles Edgar Corbin, College of the Pacific;

Mr. Frederic Warren Darling, United States Coast and Geodetic Survey;

Mr. Charles Herbert Davis, Yale Observatory;

Mr. Joseph Oscar Eckersley, Department of Plant and Structures, New York City;

Mr. Jekuthiel Ginsburg, New York City;

Mr. Kut William Halbert, Harvard University;

Dr. Victor August Hoersch, University of Illinois;

Mr. Julian Laurence Holley, Harvard Uriversity;

Dean Charles Ellsworth Horne, College of Agriculture and Mechanic Arts, Mayaguez, Purto Rico;

Professor Charles Applewhite Isaacs, State College of $\mathrm{W}^{\top}$ ashington;

Dr. Hamilton M. Jeffers, University of Iowa;

Professor William H. Kirchner, University of Minnesota;

Professor Alois Francis Kovarik, Yale University;

Mr. Harry Isler Lane, University of South Dakota;

President William Orville Mendenhall, Friends University;

Mr. Aristotle Michal. Rice Institute;

Miss Helen Moon, Lincoln National Life Insurance Company, Fort Wayne, Ind.;

Miss Thirza Adaline Mossman, Kansas State Agricultural College;

Professor George Alexander Newton, Trinity University;

Mr. Frank C. Ogg, University of Illinois; 
Professor James Robert Overman, State Normal College, Bowling Green, Ohio;

Professor Arthur Pelletier, Ecole Polytechnique of Montreal;

Mr. Frederick William Perkins, Harvard University;

Professor Edward C. Phillips, Woodstock College;

Mr. Joseph Crawford Polley, Colgate University;

Mr. George Yuri Rainich, Johns Hopkins University;

Professor Charles Henry Rawlins, United States Naval Academy;

Mr. Perry Dean Schwartz, New Haven, Conn.;

Professor Jsaac F. Seiverling, State Normal School, Millersville, Pa.;

Mr. Robert Vincent Sinnott, Hartford, Conn.;

Mr. Morris Miller Slotnick, Harvard University;

Mr. Charles Calvin Steck, Tonawanda, N. Y.;

Dr. Tracy Yerkes Thomas, University of Chicago;

Mr. Kamihayashi Tokusaburo, Iwateken, Japan;

Professor Richard Chace Tolman, California Institute of Technology;

Mr. Glen M. V. Tryon, Fenton, Mich.;

Mr. George Peterkin Unseld, Technical High School, Salt Lake City;

Mr. John Russell Vatnsdal, Yale University;

Mr. Charles Weiss, New York City;

Professor Joseph Wilczewski, St. Xavier College, Cincinnati.

Fourteen applications for membership in the Society were received.

The Committee on Printing announced that arrangements were being made to print both the BuLLETIN and the TransACTions in Hamburg, Germany, during the coming year.

Announcement was made of the appointment of Professors H. E. Hawkes (chairman), E. W. Brown, J. L. Coolidge, and H. S. White as the Committee on the first Josiah Willard Gibbs lecture; of Professor E. E. Moots as representative at the inauguration of President Updegraff of Cornell College on October 19; of Professor E. V. Huntington as representative at the inauguration of President Comstock of Radcliffe College on October 20; and of ProfessorW.H. Roever, as representative at the inauguration of President Hadley of Washington University on November 10.

Votes of thanks were extended to Boston College for a gift toward the Endowment Fund; to Professor W. H. Roever for a gift toward the expenses of the membership campaign; to the Committee on Incorporation and the incorporators; and to Messrs. Clephane, Harriman, Latimer, and Putnam for legal advice, tendered without fee, in connection with the incorporation proceedings.

It was decided to hold a meeting of the Council in 
conjunction with the western meeting of the Society at Chicago in April, 1924.

A list of nominations for trustees, officers, and other members of the Council was adopted unanimously and ordered printed on the ballot for the annual election.

President Veblen presided at the sessions of the Society, relieved in the morning by Vice-President $\mathrm{H}$. W. Tyler and in the afternoon by Ex-President E. W. Brown. The first part of the afternoon session was devoted to a paper read, at the request of the Programme Committee, by Professor Anna J. Pell, on Bilinear and quadratic forms in infinitely many variables. Titles and abstracts of the other papers read at this meeting follow below. Professor Pólya was introduced by Professor Birkhoff. Dr. Douglas's second paper, and the papers of Professor Lipka, Professor Pólya, Dr. Murray, and Professors Alexander and Richardson were read by title.

1. Professor L. P. Eisenhart: Spaces of continuous matter in general relativity.

If the field equations for a perfect fluid are taken as

$$
R_{i j}-\frac{1}{2} g_{i j} R=-k\left(\sigma u_{i} u_{j}-p g_{i j}\right)
$$

where $R_{i j}$ is the contracted Riemann tensor with respect to the fundamental tensor $g_{i j}, R$ is the scalar curvature, and $\sigma$ and $p$ are scalars, the determinant equation $\left|R_{i j}+\varrho g_{i j}\right|=0$ has a simple root and a triple root with simple elementary divisors. Conversely, when the roots of this equation for a space satisfy these conditions and at each point the fundamental quadratic form is reducible to $-d x_{1}^{2}-d x_{2}^{2}-d x_{3}^{2}+d x_{4}^{2}$ at each point, the space may be interpreted as the space-time continuum of a perfect fluid. If $\varrho^{\prime}$ is the simple root and $\varrho^{\prime \prime}$ the triple root, then $\sigma=\left(\varrho^{\prime}-\varrho^{\prime \prime}\right) / k$ and $p=\left(\varrho^{\prime}+\varrho^{\prime \prime}\right) / 2 k$. The contravariant components $u^{i}$ of the line of flow are given by

$$
\left(R_{i j}+\varrho^{\prime} g_{i j}\right) u^{i}=0 .
$$

2. Professor J. K. Whittemore: The deformation of ruled surfaces.

In this paper it is shown that the equations of any ruled surface, rulings $u$ constant, whose linear element is 
given by $d s^{2}=\left[(v-\alpha)^{2}+\beta^{2}\right] d u^{2}+d v^{2}$, where $\alpha$ and $\beta$ are arbitrary functions of $u$, are $x=A v+\int(P \beta-L \alpha) d u$ with similar equations for $y$ and $z$, where $A, L$ and $P$ are the cosines of the angles of the $x$-axis and the tangent, principal normal, and binormal, respectively, of a curve of unit curvature and arbitrary torsion, and $u$ is the arc of this curve. A property of the surface depending on the torsion of this curve is given. The method consists in determining from the Codazzi equations the single unknown coefficient of the second fundamental form of the required surface, then integrating the partial differential equations for the direction cosines of the normal and the tangents to the parametric curves.

3. Mr. G. Y. Rainich: Analytic vector functions.

This theory is analogous to the theory of analytic functions of a complex variable; the place of the complex number is occupied by the three-dimensional vector and the part of the product is played by a bilinear vector function, the basis. An analytic function is defined with the aid of a power series; the region of convergence is a parallelepiped or an elliptic cylinder; the condition of analyticity is given by a set of two differential vector equations (analogy with the CauchyRiemann equations) or by the vanishing of a contour integral (analogy with the Cauchy-Morera theorem). These functions have no independent importance, because all functions analytic on the same basis have one or three directions along which they have particular properties. To get rid of this peculiarity we consider analytic functions of two variables; substituting for each of these variables a linear vector function of the same variable $z$ we get a function of $z$ which we call semi-analytic; the functions of a semianalytic class are characterized by one differential vector equation or by the vanishing of a surface integral; they can be expanded into double series. Analogous functions can be formed also starting from ordinary analytic functions.

4. Dr. Jesse Douglas: Systems of $\infty^{2 n-2}$ curves in a Ricmann space in which the sum of the angles of every triangle formed by three of the curves is two right angles.

This paper proves the following theorem. If in a Riemann space of three or more dimensions, $d s^{2}=\Sigma a_{i j} d x^{i} d x^{j}$, there exists a system of $\infty^{2 n-2}$ curves, defined by a set of differential equations of the form $d^{2} x^{i} / d s^{2}=F_{i}(x, d x / d s)$, which has the 
property that in every triangle formed by three of the curves the sum of the angles is equal to $\pi$, then the Riemann space must be conformally equivalent to a euclidean space, and in such a way that the $\infty^{2 n-2}$ curves correspond to the straight lines of the euclidean space.

5. Dr. Jesse Douglas: Necessary and sufficient conditions that a system of $\infty^{4}$ curves in space consist of the mutual intersections of $\infty^{3}$ surfaces.

The $\infty^{4}$ straight lines of space are the mutual intersections of the $\infty^{3}$ planes. Not every system of $\infty^{4}$ curves $n$ space has a so related system of $\infty^{3}$ surfaces. Assuming the curve system to be defined by the differential equations $y^{\prime \prime}=F\left(x, y, z, y^{\prime}, z^{\prime}\right), z^{\prime \prime}=G\left(x, y, z, y^{\prime}, z^{\prime}\right)$ the present paper derives necessary and sufficient conditions in the form of three partial differential equations of the second order bearing on $F$ and $G$.

6. Professor Joseph Lipka: On Ricci's coefficients of rotation.

Ricci's coefficients of rotation, $\gamma_{i j k}$, play an important rôle in the absolute calculus of any space whatsoever. He first defines the $\gamma$ 's analytically and then shows their geometric meaning be means of the tangent spaces. Following a suggestion made to the writer by Professor Levi-Civita, the $\gamma$ 's are here defined geometrically by means of the notion of parallelism. As a consequence, the expressions for the geodesic curvature and several other invariants in terms of the $\gamma$ 's are all found and interpreted intrinsically. Applying the notion of conformal parallelism, the $\gamma$ 's are generalized so that they involve an arbitrary function of the coordinates, and geometric interpretations of certain invariants in the generalized coefficients are given.

7. Professor Joseph Lipka: Types of alignment charts in three variables.

This paper contains a study of a systematic classification of alignment or nomographic charts, based upon parallel coordinates. In particular, it gives the specific form which an equation in three variables, $f(u, v, w)=0$, must have in order that it may be represented by certain combinations of curved and straight line scales. It also gives the equations of the scales in each case, and their method of construction. 
8. Professor Georg Pólya: On the mean-value theorem corresponding to a given linear homogeneous differential equation.

This paper, which will appear in the Transactions of THIS SOCIETY, deals with the conditions which must be imposed on a linear differential form $L(y)$ of the $n$th order in order that whenever $y$ vanishes $n+1$ times on the given interval, $L(y)$ shall necessarily vanish on that interval at least once.

9. Dr. F. H. Murray: Note on stability à la Poisson.

This paper appears in full in the present issue of this Bulletin.

10. Professor J. W. Alexander: On infinitely connected plane regions.

Some theorems are proved on the topology of infinitely connected plane regions, and a class of regions is determined such that each region is characterized by a pair of invariants, one finite, the other transfinite.

11. Professor J. W. Alexander: On the deformation of an $n$-cell.

Let $r^{\prime}=R(r, \theta), \theta^{\prime}=\Theta(r, \theta)$ be the equations of a oneto-one continuous transformation $T$ carrying the interior and boundary of the unit circle into itself and leaving all points on the boundary of the unit circle invariant. The transformation may be extended to the entire plane by saying that it leaves all points without the unit circle invariant. Construct, now, a transformation $T_{\lambda}$ such that $r^{\prime}=\lambda R(r / \lambda$, $\theta), \theta^{\prime}=\Theta(r / \lambda, \theta)$ for $\lambda>0$ and such that $T_{0}$ is the identity. Then, as $\lambda$ varies from 0 to $1, T_{\lambda}$ determines a one-toone continuous deformation generating the transformation $T$ and leaving the boundary of the unit circle pointwise invariant. The theorem generalizes to $n$ dimensions.

12. Professor R. G. D. Richardson: On the reality of the zeros of a $\lambda$ determinant.

This paper appeared in full in the December number of this Bulletin.

13. Professor E. V. Huntington: Sets of completely independent postulates for cyclic order.

The author gives two sets of five postulates for the theory 
of cyclic order, each set being shown to be "completely independent" in the sense of E. H. Moore. An abstract of some of the results appeared in the ProceEdINGS OF THE National ACademy, vol. 2 (1916), pp.630-631. The paper is closely related to the exhaustive treatment of Sets of independent postulates for betweenness, published by E. V. Huntington and J. R. Kline in the Transactions OF THIS SocIETY, vol. 18 (1917), pp. 301-325, though the results in the present case are much more easily obtained. The paper will be offered to the Transactions.

14. Professor Dunham Jackson: Some corollaries of Bernstein's theorem.

The theorem of Bernstein referred to in the title states that if $T_{n}(x)$ is a trigonometric sum of order $n$, and if $\left|T_{n}(x)\right| \leqq L$ for all values of $x$, then $\left|T_{n}^{\prime}(x)\right|$ can never exceed $n L$. The hypothesis requires that the condition on $\left|T_{n}(x)\right|$ be satisfied for all (real) values of $x$, or, what amounts to the same thing, that it be satisfied throughout an interval of length $2 \pi$. The present paper obtains results of similar character, though less simple in form, on the assumption merely that the condition is satisfied throughout an interval of length less than $2 \pi$, the conclusions then being valid for the restricted interval also. These results are deduced indirectly from Bernstein's theorem itself.

15. Dr. E. L. Post: Theory of generalized differentiation.

The theory of derivatives of non-integral orders, begun by Liouville and Riemann, may be said to be complete. On the other hand, the theory of more general operators considered as functions of $D$, the derivative, is fragmentary. In the present paper, the problem is attacked by an entirely new method, and results are obtained that generalize those of Riemann. Although the present investigation was inspired purely by an interest in the bizarre, it has been found to connect with many fields in the most recent branches of analysis. In particular, it has applications in the theory of the Laplace transformation, Volterra's permutable functions and functions of composition (of the closed cycle group), and the Heaviside operational classes.

R. G. D. RichaRdSON, Secretary. 